\title{
A Model of Work Effort and Productive Consumption*
}

\author{
Frank P. Stafford and Malcolm S. Cohen \\ Department of Economics and Institute of Labor and Industrial Relations, \\ University of Michigan, Ann Arbor, Michigan 48104
}

Received May 2, 1973

\section{INTRODUCTION}

Models of labor supply developed by economists generally make no provision for the intensity of on-the-job work effort of the individual despite the fact that studies of performance conducted by industrial psychologists have demonstrated that output varies substantially over the work period. It is typically found that toward the end of the work period output falls, particularly in taxing jobs, but can rise in more pleasurable work. ${ }^{1}$ Moreover, while it is common for economists to assume that at some point marginal wages are lower than average wages, no explicit economic theory predicts this divergence; usually some reliance is placed on technological or institutional factors which effect diminishing marginal wages.

The dynamic model we develop is consistent with most empirical research of economists and industrial psychologists, but the model also generates some implications which are not apparent from casual thought about work effort and which can be tested empirically. The model can be used to derive a path of work effort, market expenditure, and wages based on choices made by individuals rather than on institutional factors and suggests that at work consumption effort and market expenditures for consumption can move in opposite directions: while workers can slack off in work effort at the end of the work period (allocate more effort to on-the-job consumption), they may simultaneously cut back on market expenditures for on-the-job consumption.

* An earlier version of this paper, "Labor, Leisure and Amenities Over the Day," was first presented at the 1971 Meetings of the Econometric Society. The authors would like to acknowledge the Manpower Administration of the Department of Labor and National Science Foundation Grants GS3010 and GS31639 for research support and Alan Deardorf, Elmer Gilbert, C. Russell Hill, William Powers, and Lester Taylor for comments. The comments of a referee were particularly helpful in revising an earlier version of the paper. The authors alone assume responsibility for any errors.

${ }^{1}$ For a discussion, see Maier [6].

Copyright (C) 1974 by Academic Press, Inc. 
The goal of our paper, then, is to develop a model which will derive the conditions for a diminishing marginal wage and to portray the path of various choice variables over the work day. While to this date research by economists on what happens within the work period is scant, it is our belief that implementation of proposed national surveys to measure time allocation over the entire day on a diary basis will encourage empirical work in this area. ${ }^{2}$ Further, we hope to test some of the implications of the current model or a variant of it when such data become available.

Analytically, our model is similar to those developed to explain lifecycle investment in human capital. ${ }^{3}$ That is, the individual is specified to be choosing a path of investment in an intermediate good-here, a psychological state variable rather than human capital. In both our model and in the human capital models, the problem concerns a finite horizon. Hence, there are incentives to cease investing in the intermediate good as the terminal time approaches. The major difference is that we take human capital or wage potential at the beginning of the work period as given and concentrate on optimal time allocation over the period of a day.

\section{A MODEL}

\section{A. The General Model}

The general problem of allocation of time over the day could be treated in a rather simple model, as follows. Utility would depend on a home activity $Z_{h}$ and a work activity $Z_{w}$, each of which requires time and market goods. To account for fatiguing effects, the wage rate would be taken as a function of working time (first rising with working time, then falling), but this dependence can be modified by investments or productive consumption. Yet the feature which would not be captured in this model is the time ordering of activity over the day, and we seek to portray this behavior as well as the average daily levels of the activities.

The basic means of developing our model is to introduce the notion of productive consumption by noting that at each point in time consumption on the job as determined by work pace and by market inputs on the job (purchased for the employee by the employer or purchased directly by the employee) enhances the worker's potential productivity. Further, consumption on the job is a part of the worker's satisfaction over the

2 F. Thomas Juster and John Robinson of the Survey Research Center, University of Michigan, have been developing a pilot project.

${ }^{3}$ For example, Ben-Porath [2], Ghez and Becker [4], Stafford and Stephan [10]. 
day and this renders our model consistent with usual discussions of "net advantages."' While on the job, a worker divides his effort between actual work and consumption. His consumption effort per unit time plus the market inputs per unit time are the arguments of the on-the-job utility function at each point in time. While on the job, the worker's potential productivity erodes but this erosion can be slowed up (or even possibly reversed) through utility flows determined by consumption effort and market inputs. Basically, then, on-the-job consumption is an intermediate as well as a final good.

At work, the individual's utility function is ${ }^{\bar{b}}$

$$
U_{1}=g\left(s, m_{1}\right),
$$

where $s=$ percent of effort per unit time allocated to consumption with $0 \leqslant s \leqslant 1 ; m_{1}=$ market goods per unit time allocated to satisfaction while on the job. This can range from "free" coffee to more pleasant (expensive) decor. The price of $m_{1}$ is $p_{1}$.

At home, utility is a function of market goods per unit time. By definition, all effort is put into nonmarket activity:

$$
U_{2}=h\left(m_{2}\right)
$$

where $m_{\mathrm{\Omega}}=$ market inputs per unit time while at home. This could be different from the basket of market inputs available for consumption at work.

The individual's objective is to maximize the sum of the integrals of consumption at home and at work. The utility functions (1) and (2) have the usual properties, and, further, the satisfaction per unit time for consumption at home must be greater to reflect the fact that it is easier to "produce" consumption at home than at work in order to motivate positive home time. ${ }^{6}$ It should be noted that since we are speaking of the same person at home and at work we do not really mean by (1) and (2) that his preferences differ at home and at work. Rather, in the context of the research on household production models, we mean that the technology for on-the-job consumption implies that the set of goods consumed at home may be very expensive when one is at the place of work.

${ }^{4}$ Marshall [7].

${ }^{5}$ All variables are time subscripted.

${ }^{6}$ For this interpretation of consumer behavior wherein market inputs and time are combined to produce more basic commodities, see Becker [1]; our use of a state variable in consumption behavior is similar to the state variable approach of Houthakker and Taylor [5]. However, in our model, the state variable applies to an intermediate good rather than a final good. 
In this problem we can break the time interval of a day into two parts. During the first (work) part, the equations of motion of the model are

$$
\begin{aligned}
& \dot{R}=(1-s) \alpha \Pi-m_{1} p_{1} \\
& \dot{\Pi}=g\left(s, m_{1}\right)-\delta \Pi,
\end{aligned}
$$

where $R=$ financial assets with the worker paid his marginal net wage of $(1-s) \alpha \Pi-m_{1} p_{1} ; \Pi=$ potential productivity in physical units; ${ }^{7}$ $\alpha==\mathrm{a}$ wage rate per unit of potential productivity which is assumed constant; $\delta=$ depreciation rate of potential productivity due to erosion of productivity while on the job. A taxing or unpleasant job results in a high rate; $t_{0}=$ initial time starting at work; $t_{1}^{-}=$time just prior to end of the work period which is endogenous.

The individual's potential productivity prior to work is given exogenously by education, training, and other factors including short-run phenomena (a bad night's sleep). In a more complex model, one might introduce consumption at home (from the previous period) as a factor influencing $\Pi\left(t_{0}\right)$. Although in our next section we discuss the implication of interdependence between home consumption and on-the-job productivity and the role of human capital, here we assume that slecp restores the individual to a given exogenous value of $\Pi\left(t_{0}\right)$ regardless of his previous day's home consumption.

At home, the model simplifies to (2) plus the following equation of motion:

$$
\dot{R}=-m_{2} p_{2} \quad t_{1}^{+}<t \leqslant t_{f},
$$

where $p_{2}=$ the price of goods at home, $t_{1}{ }^{+}=$time just after ending work, and $t_{f}=$ end of the day.

Now, at the switching time, $t_{1}$, financial assets change discontinuously since there is a given monetary travel cost, $c$. Thus,

$$
R\left(t_{1}^{-}\right)-R\left(t_{1}^{+}\right)-c=0 .
$$

${ }^{7}$ In a more complex model, one could specify different consumption activities which would differ in terms of their effect on productivity. Some activities might even have a negative influence on productivity on the job (e.g., beer drinking).

${ }^{8}$ One could argue that this depreciation rate is a function of work effort. Working too hard has an increasingly large reduction in potential productivity due to excessive fatigue effects, and, hence, it is better to "pace" work effort. For simplicity, we ignore this possibility. 
The necessary conditions for an optimum can be derived by defining

$$
\begin{aligned}
\Phi & =v\left[R\left(t_{1}^{-}\right)-R\left(t_{1}{ }^{+}\right)-c\right], \\
H_{1} & =g\left(s, m_{1}\right)+\lambda_{R}\left[(1-s) \alpha \Pi-m_{1} p_{1}\right]+\lambda_{m}\left[g\left(s, m_{1}\right)-\delta \Pi\right], \\
H_{2} & =h\left(m_{2}\right)+-\lambda_{R} m_{2} p_{2} .
\end{aligned}
$$

Then the necessary conditions are given by (3), (4), and (5) and

$$
\begin{gathered}
\dot{\lambda}_{R}=-\partial H_{1} / \partial R=-\partial H_{2} / \partial R=0 ; \quad t_{0} \leqslant t \leqslant t_{f}, \\
\lambda_{\pi}=-\partial H_{1} / \partial \Pi=\lambda_{R} \alpha(s-1)+\delta \lambda_{\pi}, \\
\partial \Phi / \partial R\left(t_{1}^{-}\right)=v=\lambda_{R}\left(t_{1}^{-}\right) ; \quad \partial \Phi / \partial R\left(t_{1}^{+}\right)=v=\lambda_{R}\left(t_{1}^{+}\right), \\
H_{1}\left(t_{1}^{-}\right)-H_{2}\left(t_{1}^{+}\right)=0 \\
\partial H_{1} / \partial m_{1}=0 ; \quad g_{n_{1}}=\lambda_{R} p_{1} /\left(1+\lambda_{\pi}\right) \\
\partial H_{1} / \partial s=0 ; \quad g_{s}=\lambda_{R} \alpha \Pi /\left(1+\lambda_{\pi}\right) \\
\partial H_{2} / \partial m_{2}=0 ; \quad h_{m_{2}} / p_{2}=\lambda_{R} .
\end{gathered}
$$

In this case the necessary conditions have their usual interpretations for the two subarcs but the time of switching activities, $t_{1}$, is also determined by (11.1) and (11.2). ${ }^{9}$ From the model it is clear that the length of the work arc would be shortened by a pure income effect because we assume that consumption is more "easily produced" at home. As in static models, a rise in the wage rate (larger $\alpha$ ) would have both income and substitution effects. ${ }^{10}$

A few initial comments can be made about the nature of the necessary conditions for an optimum. First, decisions for an optimum over the interval $t_{0} \leqslant t \leqslant t_{1}{ }^{-}$require that initial values of $\lambda_{\pi}$ and $\lambda_{R}$ be chosen so that at $t_{1}, \lambda_{\pi}=0$ and $R>R^{0}$. The value of $\lambda_{R}$ should be chosen to meet the condition that $R=R^{0}$ at $t_{f}$. Second, the asset equation (3) is not a truly dynamic part of the model and serves only as an intertemporal budget constraint over the time interval $\left(t_{0}\right.$ to $\left.t_{f}\right)$ in question. For simplicity, we can assume $R\left(t_{0}\right)=R\left(t_{f}\right)=R^{0}$. The fact that assets have a resulting constant shadow price throughout the problem (9) simplifies matters, and a pure income effect induced, say, by a change in $R\left(t_{B}\right)>R^{0}$

${ }^{9}$ For a more complete discussion of the general control model used here, the reader should consult Bryson and Ho [3], however noting the typographical error on p. 106: $H^{(i)}+\lambda^{T} \dot{x}$ should be $H^{(i)}-\lambda^{T} \dot{x}$.

${ }^{10}$ From Eq. (10) a higher value of $\alpha$ will tend to make $\dot{\lambda}_{\pi}$ algebraically larger, but a higher value of $\alpha$ will also lower $\lambda_{R}$, hence making $\dot{\lambda}_{\pi}$ algebraically smaller. 
can be represented by a fall in $\lambda_{R}$ along a path meeting necessary conditions for an optimum.

While a more precise statement requires specification of a functional form for utility, one can reasonably infer from (12)-(14) that the pure income effect of a fall in the $\lambda_{R}$ satisfying the necessary conditions acts to increase expenditure per unit time both at work and at home and should encourage a greater fraction of effort forgone to on-the-job consumption. That is, an easier work pace is a normal good as is the expenditure on physical inputs for consumption, and this implies that effective work hours can be less elastic with respect to the wage rate than are observed hours." ${ }^{11}$

From Eqs. (9)-(14) some insight into the problem can be gained by noting that as $t_{1}$ is approached, the shadow value of potential productivity $\lambda_{\pi}$ approaches zero and further that it is clearly optimal to end the work period before $\Pi$ becomes negative. That is, $\lambda_{\pi}$ falls to zero at the end of the work subarc-although it can rise and then fall over the entire work subarc. ${ }^{12}$ While the fall in $\lambda_{\pi}$ at the end of work will act to reduce time allocated to on-the-job consumption, $\Pi$ may be falling at a sufficiently rapid rate to cause a rise in $s$ (case 1). That is, while a fall in $\lambda_{\pi}$ implies that the intermediate good value of on-the-job consumption is lessened at the end of the work period, the opportunity cost of reduced work effort may fall still faster (as $\Pi$ falls). Hence, whether or not $s$ falls at the end of the work period is ambiguous a priori. ${ }^{13}$ In the case where $s$ falls (case 2), whether or not this falling fraction of effort forgone to on-the-job consumption (and decreased expenditures) will result in increased or decreased marginal wages, $(1-s) \alpha \Pi$ (observed marginal wages are $\left.(1-s) \alpha \Pi-m_{1} p_{1}\right)$ depends on whether $\Pi \Pi$ is falling rapidly or slowly. In a more pleasurable work environment where one's productivity is not eroded rapidly (a lower value of $\delta$ ), one could observe a rise in marginal wages because $s$ could be falling sufficiently to offset the smaller decline in potential productivity.

${ }^{11}$ Effective hours, $\int_{t_{0}}^{t_{1}}(1-s) d t$, are less than observed hours, $\int_{t_{0}}^{t_{1}} d t$. If a pure income effect raises the average level of $s$, then effective hours fall relative to observed hours.

${ }^{12}$ It can be noted that conditions (12) and (13) along with the other necessary conditions enables one to solve for $m_{1}$ and $s_{1}$ as functions of $\lambda_{R}$ and the shadow prices:

$$
\begin{aligned}
m_{1} & =m_{1}\left(\left(\lambda_{R} p_{1} /\left(1+\lambda_{\pi}\right)\right), \lambda_{R} \alpha \Pi /\left(1+\lambda_{\pi}\right)\right), \\
s & =s\left(\left(\lambda_{R} p_{1} /\left(1+\lambda_{\pi}\right)\right), \lambda_{R} \alpha \Pi /\left(1+\lambda_{\pi}\right)\right) .
\end{aligned}
$$

${ }^{13}$ We know that by differentiating (13) with respect to time we have $\dot{g}_{s}=$ $\left(\lambda_{R^{\alpha}} /\left(1+\lambda_{\pi}\right)\right)\left(\dot{I}-\left(I \dot{\lambda}_{\pi} /\left(1+\lambda_{\pi}\right)\right)\right)$ and that for given $m_{1}, s$ will be rising if $\dot{g}_{s}>0$. Since $\dot{\lambda}_{\pi}$ is negative toward the end of the work arc, this will encourage a falling $s$, but since $\dot{I}$ is also negative at this point, this encourages a rising $s$. 
Another way of looking at case 1 and case 2 is to note that from the necessary conditions (12) and (13), we have

$$
g_{m_{1}} / p_{1}=g_{s} / \alpha \Pi
$$

which states that along the trajectory which satisfies the necessary conditions the ratio of marginal utility of market inputs relative to price should be set equal to the marginal utility of consumption relative to the potential wage. Toward the end of the work period, there is incentive to reduce $m_{1}$ and $g_{m_{1}}$ rises. Then, $g_{s}$ will also rise ( $s$ will fall) if $\Pi$ is falling slowly relative to $g_{m_{1}}$. It is also true that to say much more about behavior one must deal with particular functional forms. For example, toward the end of work consumption effort could tend to rise because of a rapid fall in potential productivity, while market inputs should fall by virtue of the shadow value of potential productivity approaching zero. However, if there are strong cross terms in the utility function, the rise in consumption effort would encourage a rise in market inputs. In our next section (B), we consider several extensions of the model and then turn to a simplifying specific case to exemplify several features of the model (C).

\section{B. Extensions of the Basic Model}

From our model a number of possible extensions are suggested. These include: (1) integration of home and work productivity both in terms of earnings capacity and ability to enjoy consumption at home and at work and (2) the role of travel costs.

\section{Interdependencies Between Home and Market Productivity}

Although we have specified that real income on the job enhances productivity on the job, it can also be argued that home activities enhance productivity on the job. This generalization would require a more complex model wherein the previous (home) period's consumption explicitly influences the initial condition for the psychological state (II) at work. In addition, ability to consume at home could also be dependent on one's level of the psychological state variable, and, in contrast to our model, the shadow value of $\Pi$ would not equal zero at the time of switching from work to home. If the psychological state were specified as significant in the ability to enjoy home time but were more important in determining potential wage, then the general qualitative results discussed above concerning the time path of work effort and market expenditure on the job would continue to hold.

Generally, our division between home and place of work is perhaps 
somewhat arbitrary. For example, some people do perform some income producing activity at home, at a wage (say) $w_{h}$. We are implicitly assuming that $w_{h}$ is sufficiently low so that all time at home is spent in consumption. But, in general, the distinction breaks down, and at home there can also be market and time inputs to reduce depreciation of home skill. ${ }^{14}$

\section{The Role of Travel Costs ${ }^{15}$}

Travel from place of work to home requires not only goods as we suggests but time as well. This can be accounted for easily. Let $\tau$ denote commuting time. The problem is thus to maximize

$$
\int_{0}^{t_{1}-} g() d t+\int_{t_{1}+}^{t_{f-r}-\tau} h() d t
$$

(plus utility or disutility of commuting) subject to

$$
\int_{0}^{t_{1}{ }^{-}} p_{1} m_{1} d t+\int_{t_{1}{ }^{+}}^{t_{f}-\tau} p_{2} m_{2} d t=\int_{0}^{t_{1}{ }^{-}}(1-s) \alpha \Pi d t-c
$$

where $c$ is the direct cost of commuting. The marginal price of time to commuting is identical to the marginal valuation of an extra unit of time and is given by

$$
p_{t}=\left(1 / \lambda_{R}\right)\left\{g+\lambda_{R}\left[(1-s) \alpha \Pi-p_{1} m_{1}\right]\right\}
$$

evaluated at $t_{1}-$. One line of inquiry is: Under what conditions is $p_{t}$ equal to the marginal wage at $t_{1}$ ? The answer is that homotheticity of $g$ is necessary. Proof:

$\frac{1}{\lambda_{R}}\left\{g+\lambda_{R}\left[(1-s) \alpha \Pi-p_{1} m_{1}\right]\right\}=\frac{1}{\lambda_{R}}\left\{g-\frac{\partial g}{\partial m_{1}} m_{1}+\frac{\partial g}{\partial s}(1-s)\right\}$.

So $p_{t}=\alpha \Pi$ if $g$ is homothetic. More generally, $\alpha \Pi$ would understate or overstate the value of time according as the income elasticity of demand for $m_{1}$ were greater or smaller than the income elasticity of demand for $s$.

Since $p_{t}$ is also equal to

$$
p_{t}=\left(1 / \lambda_{R}\right)\left[h-p_{2} m_{2}\right]
$$

${ }^{14}$ Another direction would be to analyze the role of human capital on productivity at home as well as at work. Work along these lines includes Michael [8] and Ghez and Becker [4].

${ }^{15}$ This discussion was developed by the referee of our earlier manuscript. 
$p_{t}$ would equal $\left(1 / \lambda_{R}\right) \partial h / \partial s_{2}$ only if $h$ were homothetic. The reason for pointing this out is because it contrasts to the simpler models of the type suggested at the beginning of Section A, where time is homogeneous, and there the value of time is always equal to the wage rate (so long as some work occurs).

Having considered some extensions and generalizations of the model, we now turn to examination of a particular example. This will provide concreteness and illustrate some of the properties of our model.

\section{An Example}

Consider the case where (1) is of the form

$$
U_{1}=\ln \left(\gamma_{0} m_{1}^{\gamma_{1}} s^{\gamma_{2}}\right) \text {. }
$$

This is the well-known form used in the Stone model [9] and elsewhere and has the analytically tractable property of separability. In this case, Eqs. (12) and (13) when expressed in terms of the optimal fraction of effort forgone to consumption $\left(\hat{m}_{1}\right)$ and market inputs $(\hat{s})$ during the work are become

$$
\begin{aligned}
\hat{m}_{1} & =\gamma_{1}\left(1+\lambda_{\pi}\right) / \lambda_{R} p_{1}, \\
\hat{s} & =\gamma_{2}\left(1+\lambda_{\pi}\right) / \lambda_{R} \alpha \Pi .
\end{aligned}
$$

To examine the nature of the solution in the work subarc, we can note that the loci for $\dot{\lambda}_{\pi}=\dot{I}=0$ are

$$
\begin{aligned}
\lambda_{\pi} & =-1+\left(\lambda_{R} \alpha+\delta\right) \Pi /\left(\gamma_{2}+\delta \Pi\right), \\
\Pi e^{\delta \pi / \gamma_{2}} & =K\left(1+\lambda_{\pi}\right)^{\left(\gamma_{1}+\gamma_{2}\right) / \gamma_{2}},
\end{aligned}
$$

where $K$ is a positive constant $\left[K=\gamma_{0}^{1 / \gamma_{3}} \gamma_{1}^{\gamma_{1} / \gamma_{2}} \gamma_{2} / \lambda_{K} \alpha\left\{\lambda_{R} p_{1}\right)^{\gamma_{1} / \gamma_{2}}\right]$.

From obvious assumptions about the signs of the parameters and for a work period of a tixed length, the loci can be represented in $\lambda_{\pi}, I I$ space. (See Fig. 1.) As a visual guide, contours of a constant $s\left(\overline{\hat{s}_{y}} \overline{\hat{s}^{\prime}}\right)$ and constant $m_{1}\left(\bar{m}_{1}, \overline{\hat{m}}_{1}\right)$ have been drawn in. ${ }^{16} \mathrm{~A}$ variety of paths is possible, but let us trace through paths $c$ and $a$ since they represent the range. In path $c$, the workday is characterized by a rise and then a fall in potential productivity. Moreover, a rise and then fall in both observed wages, $(1-s) \alpha I I-p_{1} m_{1}$, and in work productivity of the type measured by

\footnotetext{
${ }^{16}$ Derived by assuming $\hat{s}=K_{1}$ and $\hat{m}_{1}=K_{2}$ in (12') and $\left(13^{\prime}\right), K_{1}$ and $K_{2}$ are aro bitrary constants.
} 


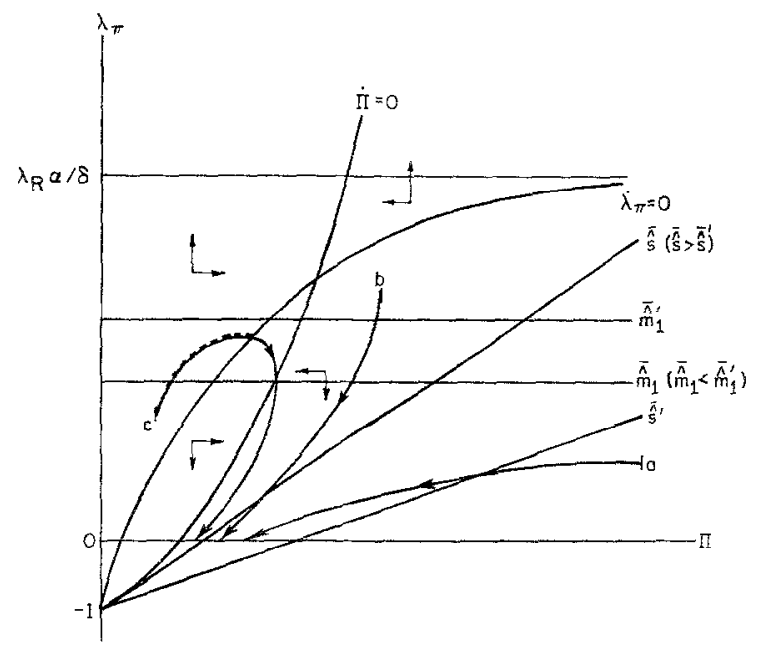

FrGURE 1

psychologists, $(1-s) \alpha I I$, is likely. That is, over part of the dashed segment, $s$ could be rising along with $m_{1}$ but at a slow enough rate to yield a rise in $(1-s) \alpha \Pi$ since $\Pi$ is also growing. Eventually, both market inputs and time inputs into on-the-job consumption fall and if $s$ is falling rapidly relative to potential productivity $(\Pi)$, then output could rise as discussed in Section A (case 2). There we noted that in more pleasurable work one could observe a rise in marginal wages because $s$ could be falling sufficiently to offset the smaller decline in potential productivity.

In contrast, path $a$ can be thought of as representing a job in which a person's productivity is rapidly eroded by work (case 1). Here, initial productive capacity far exceeds steady-state capacity (the $\Pi$ which satisfies both $\dot{\Pi}=0$ and $\dot{\lambda}_{x}=0$ ). Under these conditions, there is strong incentive to have a system of work breaks (and hence shorter work periods) either by consumption at home or by consumption in separate facilities at work (in line with our discussion in Section B). While in all cases in Fig. 1 it should be noted that $s$ could be rising, this is much more likely in cases like path a, and we have drawn path a with $s$ rising.

These arguments can be seen from plausible alterations in the slope of the iso-s curves and hence if $\alpha \Pi$ (the price of consumption time on the job) is falling rapidly relative to $\lambda_{\pi}$, the fall in the opportunity cost of on-the-job consumption time is sufficient to cause a decline in work effort at the end of the work period. However, in this case of a separable utility function, it is always better to defer an increasing level of market 
inputs for home consumption toward the end of the workday since at home it is easier to get satisfaction from a given rate of expenditure per unit time. While a nonseparable function would encourage joint changes in $m_{1}$ and $s$ (in the same direction), our separable function emphasizes that there can be economic forces operating to send the two variables in opposite directions. What this suggests is that it should be possible to observe workers slacking off in work effort $(s$ rising) toward the end of work while simultaneously reducing their market expenditures for on-thejob consumption. ${ }^{17}$ For example, work effort would fall but purchasing beverages for consumption would be saved for a more enjoyable nonwork environment.

The feature of our model which suggests a variation in $m_{1}$ during the work period requires a note of interpretation. While some market inputs for consumption can be varied during work (e.g., expenditures on coffee), other market inputs are fixed (e.g., a ventilation system) and cannot be thought of varying over the work period. For such market inputs, one can think of a continuous version of a "peak load" demand for the services, and it is to a greater extent this peak load demand that determines the level of these fixed market inputs which the employer purchases for the employee.

Another aspect of Fig. 1 is that parameter changes and resulting behavior can be represented. For example, a fall in the job-specific depreciation rate owing to removal of undesirable aspects of the work environment (e.g., excessive noise) moves the intersection of the $\dot{\lambda}_{\pi}=0$ and $\dot{I}=0$ loci to the right which implies that the maximum sustainable output of workers should rise. Altering the job environment is costly and hence the marginal net benefits of, say, noise control are obviously what matter. ${ }^{18}$

The mathematical solution of the problem requires that initial values of both $\lambda_{R}$ and $\lambda_{\pi}$ be chosen (as noted in Section A). The $\lambda_{\pi}=0$ and $\dot{I}=0$ loci are altered by changes in $\lambda_{R}$ and if the problem has a unique optimum, only one combination of initial values of $\lambda_{R}$ and $\lambda_{\pi}$ will meet the corresponding boundary conditions at $t_{1}$ and $t_{f}$. Analytic determination of the full set of necessary conditions (3)-(14) is not feasible (because of the difficulty of solving $\left(12^{\prime}\right)$ and $\left(13^{\prime}\right)$ even with our special case. However, we have performed some simulations and the qualitative results appear not to be reversed for the case where $t_{1}$ is endogenous.

${ }^{17}$ Expenditures should not fall to zero because consumption on the job is also valued in its own right. (See Eq. (12).)

${ }_{18}$ Noise control may influence both the depreciation rate and on-the-jos consumption. 


\section{Discussion AND Conclusion}

While in the previous work/leisure choice literature there has been consideration of the role of productive consumption, there has not been a systematic attempt to ascertain how the intruduction of productive consumption influences the length of the workday, the time path of earnings forgone to consumption and level of consumption while on the job, and the observed earnings of individuals. In our model, consumption on the job influences potential work productivity which rises as the individual consumes and depreciates as the individual works (and at differential rates across the various jobs among which he might be choosing) as a function of the level of the stock. The theoretical construct of this "psychological" or productivity state variable serves the following purpose: The potential wage of an individual cannot be thought of as exogenously determined at the point in time by simply his training and expcrience; namely, his consumption and production opportunities are simultaneously determined and the notion of a unique wage for an individual which is independent of his on-the-job environment is explicitly rejected. The implications of our model are as follows:

(1) The behavior predicted by our model appears consistent with the work of psychologists. We have noted that a very likely path of production is one of a decline over time but that in jobs which are less taxing, output could rise toward the end of the work period. The pattern observed in industry is summarized by Maier [6, p. 497]:

\footnotetext{
"The general downward hourly trend [in production in the afternoon], however, reflects the condition of lowered production because of previous work and justifies the characterization of industrial fatigue. Another feature of some production curves which should be mentioned is the end spurt. It consists of a rise in production at the end of the work period and appears in some instunces only. It is possible that an end spurt always occurs, but it is not always apparent because its influence is offset by fatigue effects, which are in the opposite direction. Evidence for the end spurt is most commonly found in work that does not require physical exertion."
}

Although Maier does not clearly distinguish between work effort and potential productivity, in terms of our model a falling fraction of effort allocated to on-the-job consumption (case 2) is an "end spurt" of effort, but as Maier notes, even with increased effort toward production $(1-s$ rises) output need not rise because of fatigue effects (a declining $\Pi$ ). Our model also points out a case implicit in Maier's discussion, namely, the case where work effort $(1-s)$ falls at the end of the work period (case 1). In addition, our model suggests that even in this case where consumption effort rises at the end of the work period market inputs 
consumed can fall. Further, in our example with a separable utility function, the model definitely shows that there are economic forces pushing the two variables in opposite directions.

In summary of Maier's discussion, our model suggests a continuum of jobs from those with pleasant working conditions and low on-the-job depreciation of productivity to those where one's productivity erodes very rapidly and is not effectively replenished by pleasant working conditions. At the one extreme, work effort and observed productivity would rise at the end of the work period. In the intermediate cases, work effort would rise but not enough to offset declining productivity. At the other extreme, work effort would fall along with potential productivity and marginal wages would diminish sharply.

(2) Although our discussion has focused on the path of work effort, our model is consistent with the approach of equalizing net advantages and, in addition, makes explicit the relation between work environment and level of consumption while on the job. For example, a job which has unpleasant working conditions can, in equilibrium, shorten the workday as well as discourage interest in consumption on the job because simply remaining on the job for an extended period of time in itself erodes one's ability to perform effectively (as represented by potential productivity). Further, consumption effort appears to be a normal good, and, hence, effective hours supplied could have an algebraically smaller supply elasticity with respect to the wage rate $(\alpha)$ than observed hours. Behavior of market inputs consumed per unit time while on the job is less ambiguous and should rise with the wage rate since the wage rate rising acts to lower $\lambda_{R}$. (See, for example, (12) and (13').)

Employers would like to raise the output of workers and increase employee satisfaction if the cost of doing so is less than the benefits they derive. Alternatively, they are interested in cutting capital and operating costs. From the point of view of the firm, choosing a lesscostly technology which, let us suppose, implies an unpleasant work environment will require that they alter the level of consumption at work, the time path of consumption at work, and hours of work as well as presumably requiring they offer higher wages to attract and retain labor. This set of adjustments will take place via market adjustments which we have not developed in our model; our purpose is to begin by considering the optimal choice by workers given the possible characteristics of a job. Our analysis implies that adjustments can occur within a given job environment, and, hence, job choice can be effected by choice within a given job type in addition to the more commonly emphasized possibility of choosing among various possible jobs. While our model may not be 
readily adaptable to industries characterized by institutional rigidities in hours and working conditions, it has relevance for a great many industries. Even some industries viewed as traditionally rigid, such as the automobile industry, are plagued by worker "boredom" and are considering flexible hours and greater variety in working conditions and work pace.

(3) Our approach provides a conceptual framework for dealing with other questions in the labor supply literature. For example, the notion of diminishing marginal wages has been introduced largely through arguments for institutional limitations on work choice (such as low wages on a possible second job). Our explanation need not rule out institutional influences but does demonstrate a falling marginal wage as part of an intertemporal choice process. Consequently, even if one were selfemployed, there would be an optimal time to return from work and enjoy leisure because the diminishing productivity can be only partly replenished by consumption on the job. In fact, our model essentially spells out an optimal division of labor over time and as such could be used to explain the temporal specialization of individuals in a nonmarket economy as well as in a market economy.

(4) Choice of time allocation between various work and nonwork activities requires not only what fraction of a longer time span (such as a year) is spent in work and nonwork activities, but also the number of switches between work and nonwork activities. This is true not only for the division of time between home and work but also for the division of time between diligent effort and extended work breaks while on the job. This issue has not been treated explicitly, but we have allowed for it by considering a work period rather than a day. While "home" and "work" are possible designations, our model can also be thought of as applying to "work" and "noon break".

\section{REFERENCES}

1. G. S. BeCKer, A theory of the allocation of time, Econ. I. 75 (1965), 493-517.

2. Y. Ben-Porath, The production of human capital and the life cycle of earnings, J. Polit. Econ. 75 (1967), 352-65.

3. BRyson and Ho, "Applied Optimal Control," Ginn and Company, Waltham, MA, 1969 , pp. 106-108.

4. G. GHEZ AND G. BECKER, The allocation of time and goods over the life cycle," Center for Mathematical Studies in Business and Economics, The University of Chicago, Report No. 7217, 1971.

5. H. Houthakker AND L. TaYlor, "Consumer Demand in the United States: Analyses and Projections," 2nd ed., Harvard University Press, 1970. 
6. N. R. F. MaIeR, "Psychology in Industry," 3rd ed., Haughton Miffin Company, Boston, 1965, pp. 496-504.

7. A. Marshail, "Principles of Economics," 8th ed., Macmillan, London, 1961 (reprinted), p. 557.

8. R. T. Michael, Education in non-market production, J. Polit. Econ. 81 (1973), 306-327.

9. R. STONE, Linear expenditure systems and demand analysis: An application to the pattern of british demand," Econ. J. 64 (1954), 511-527.

10. F. P. STAFFord AND P. E. STEPHAN, Labor, leisure and training over the life cycle, paper presented at the 1972 meeting of the Econometric Society. 